\title{
SMART REGIONS - OPPORTUNITIES FOR SUSTAINABLE DEVELOPMENT IN THE FUTURE
}

DOI: http://dx.doi.org/10.18509/GBP.2020.62

UDC: 332.146.2]:711.45:004.738.5(4-672EU)

\author{
Kliment Naydenov \\ Sofia University "St. Kliment Ohridski, Bulgaria
}

\begin{abstract}
The global demand for environmental technologies, eco-friendly products and services and sustainable design ideas is expected to gather speed in the coming years. To promote a more resource efficient, greener and more competitive economy it is clear that the way ahead has to include significant innovation: sustainable growth needs to go hand in hand with smart growth in order for the EU regions and its citizens to reap the full benefits of a switch to the green economy. To achieve socio-economic development and create jobs, it is essential to connect sustainable and smart growth, in particular, through the research and innovation strategies for smart specialization. It is also important to find practical solutions to de-coupling economic growth from environmental degradation. Innovation is at the core of the efforts to shift Europe's economy and society towards a resource efficient and low-carbon future. The promotion of innovation for sustainable growth requires an holistic approach and a long-term perspective across the policy cycle. Regional economies are keys to innovation and growth. There is a wealth of evidence and practical examples, which confirms that regions and cities play an important role in developing innovation by being the home of industrial clusters, competence centers, incubators, technology parks and many other types of formal and informal innovation spaces. Successful regions and cities become European or global nodes of innovation, technology networks and value chains. regions and localities also play a significant role in pursuing sustainable development mainly due to their proximity to many environmental problems, as well as to local know-how on how to prevent and adapt to environmental challenges.
\end{abstract}

Keywords: smart regions, smart cities, digital region, smart economy

\section{INTRODUCTION}

The digital revolution of recent years has greatly transformed people's lives and jobs by enabling unprecedented organizational and networking capacities with significant consequences for work processes and daily life, as well as for urban spatial organization and planning, beginning with the improvement of worldwide communications and transports, urban systems efficiency, and the knowledge-based economy [6]. Cities and regions globally are increasingly shifting towards innovation, bringing digitization and the Internet of Things (IoT) into all aspects of human and business life. This movement is taking place in order to apply these technologies to addressing challenges while maintaining liveability. Smart cities are able to attract and retain talent and to grow their economy, while those that do not embrace this change will risk losing key demographics, resulting in economic, environmental and even social decline. Smart places are magnets for knowledge, talent, creativity, high value jobs and investment. The 'smart cities' is a new concept and it measures not how smart the city is, but the city's efforts to make 
itself smart - sustainable development, sound economic growth, and when the urban system adapts itself to the users' needs. The smart city concept incorporates good urban planning, use of digital technologies, networks of technologies, networks of people who work together well, a change in the way of thinking, the transformation of the city governments for successful smart cities and applying the participatory approach [7]. These days, the world is full of "smart cities" and "smart regions". They proliferate rapidly as new digital technologies are applied to enhance daily life. Smartness is "in", it is "cool", and the labels proliferate 1]. The concept of Smart Regions is based on the vision of more cost-effective public administration. This vision comes after a period of de-industrialization and growing populations in cities. Growing populations in growing cities require better public services. At the same time, there is growth in new information technologies, which creates a new market and forms the basis for new industrial growth [2]. Although the conceptual framework of a smart territory (city or region) is often understood as a single quality, a more structured definition requires us to examine alternative characteristics. This would allow us to understand the factors behind the ability of some regions to achieve high levels of "smartness", and to provide potential policy conclusions. As a result, the concept of "smart" was divided into six pillars [3]:

- Smart Economy,

- Smart Governance,

- Smart Mobility,

- Smart Society,

- Smart Living,

- Smart Environment.

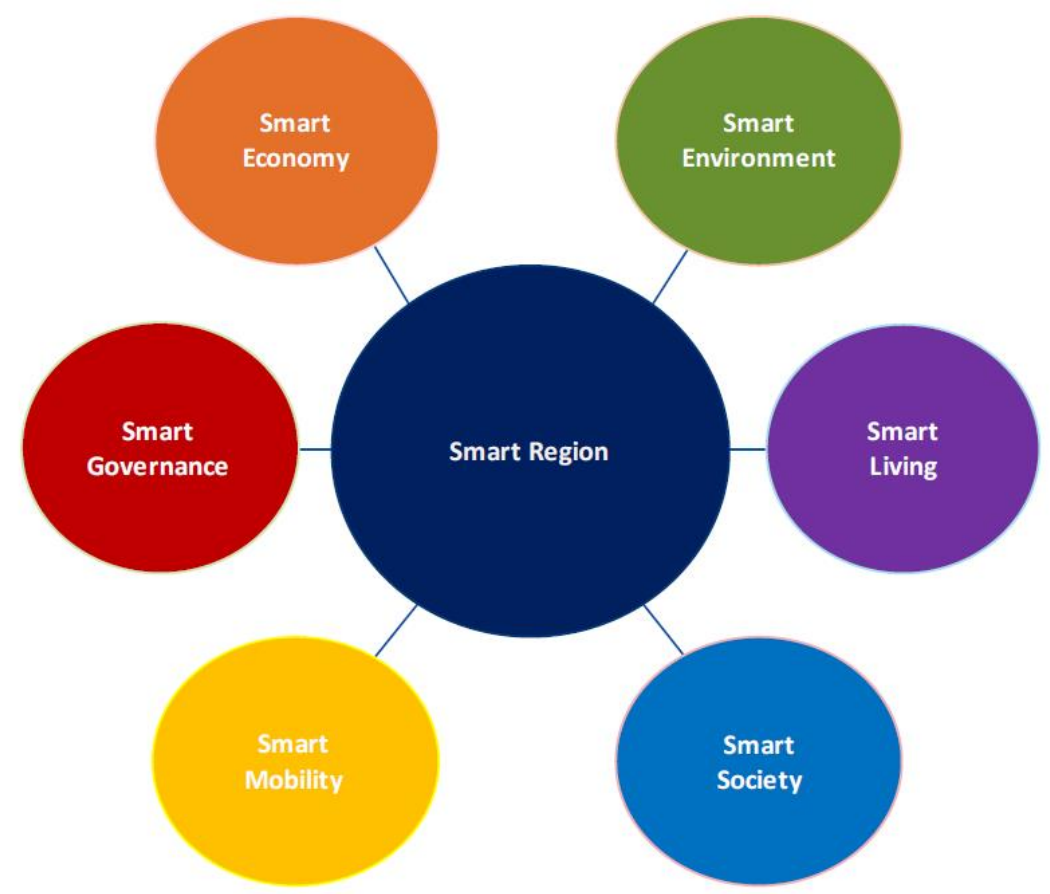

Figure 1. The conceptual framework of the Smart Region Index

Source: Kollar M., R. L. Bubbico, N. Arsalides Smart Cities, Smart Investment in

Central, Eastern and South-Eastern Europe, A report by the EIB Economics Department, 2018

\section{DATA \& METHODS}

In the article are used primary data and secondary sources and the use of both, which is termed triangulation, or dual methodology. Primary data, which we used, is the data 
collected by us, i.e. interview, observation, questionnaires. Secondary sources used in the article are data that already exists - previous research, official statistics, mass media products, government reports, web information, historical data and information.

\section{DISSCUSION}

Smart Economy comprises variables affecting competitiveness, for instance, innovation performance, and degree of entrepreneurship, trademark applications and technological utilization by firms. Smart Environment is defined by six variables explaining clean environmental procedures, the amount of pollution and environmental resource management. The Governance pillar includes indicators explaining the quality of services and the strength of regulations and administration procedures. Smart Living captures the fundamental aspects of quality of life such as Internet use, cultural factors, health conditions and the level of safety in a region. Additionally, when it comes to the variables that define Smart Mobility, both local and international accessibility factors were taken into consideration. Finally, the Society pillar includes variables explaining the citizens' level of education, creativity and the quality of employment in the region [3]. Smart places are more than just places where technology is overlaid on a urban or rural landscape. They have to integrate with more traditional spatial values of liveability, community, health, sustainability and economic resilience.

The smart region really means the "digital" region - a concept that has no clear definition so far. However, experts agree that the smart region should not be seen in a narrow sense as a technology-packed region. Rather, technology in this case is a tool, an instrument for achieving a common goal, namely the creation of a comfortable regional environment. In our opinion a Smart Region is a large area, of mixed urban and non-urban use, where smart technologies have been deployed to benefit the economic growth, quality of life and wellbeing of citizens in the territory in connection with sustainable development and climate changes. Making a region "smart" is most often based on implementing urban innovation in three main areas. These are transport to improve residents' mobility and reduce congestion by offering alternative modes of transportation, an environment that includes water management, energy, air quality and waste, and the overall improvement of the lives of people who they live in the city.

Smart specialization is Europe's transformation agenda for the next decade, and it requires a well-orchestrated regional ecosystem to work effectively. Within this constellation, notions of knowledge creation and the translation of knowledge into practice are becoming increasingly important and are taking new forms. Europe needs entrepreneurial and pioneering regions with practices that integrate top-down policy making with bottom-up self-renewal to create effective policy. Diverse European documents and policy papers attest to these needs (CoR, 2013). Smart specialization aims to support regions in addressing this challenge. In these regions, all societal partners need to work together, and joint learning is a cornerstone of this collaboration. Universities are an important instrument for codifying the lessons learned and helping other actors take the learning to the next level of practice. They are beginning to play this role in regional innovation ecosystems, making smart regions smarter and supporting diverse regional players in collaborating effectively. This is the context called for in diverse policy papers and strategy documents. In this article, we describe how this works in practice, focusing on the contributions universities make to smart regions, and using the experiences of Finland's Helsinki Region in creating and realizing its smart specialization process [1]. The concept of Smart Region is an extension and the next phase in the development of a 
Smart City model, which recognizes that, in order for the region to achieve our smart potential future, we need to consider the opportunities, benefits and challenges that smart technologies can offer beyond the traditional applications in a mostly urban context. Data does not stop at urban boundaries. According to regional planning objectives, "smart regions" can be defined as "knowledge regions", "digital regions", "cyberregions" or "ecoregions" according to regional planning objectives. The economic and social smart regions are looking to the future. They continuously monitor the most important infrastructure - roads, bridges, tunnels, railways, subways, airports, seaports, communication systems, water supply, power supply, even important buildings - in order to optimize resource allocation and ensure safety. Collaboration on a regional level ensures smaller communities can tap into a larger body of knowledge. Smart region approach can pave the way for such digital inclusion and innovation. In these regions, the number of services provided to the population is steadily increasing, ensuring a sustainable environment that promotes well-being and the preservation of public health. All of these services are based on ICT infrastructure.

The concept of a Smart Region is derived from the similar concept of a Smart City, where a shared technological infrastructure is used to benefit citizens in a particular urban area. The concept of Smart Region is much broader and considers smart technologies deployed throughout a larger geographical area, which might englobe our metropolitan, urban settlements, as well as non-urban areas.

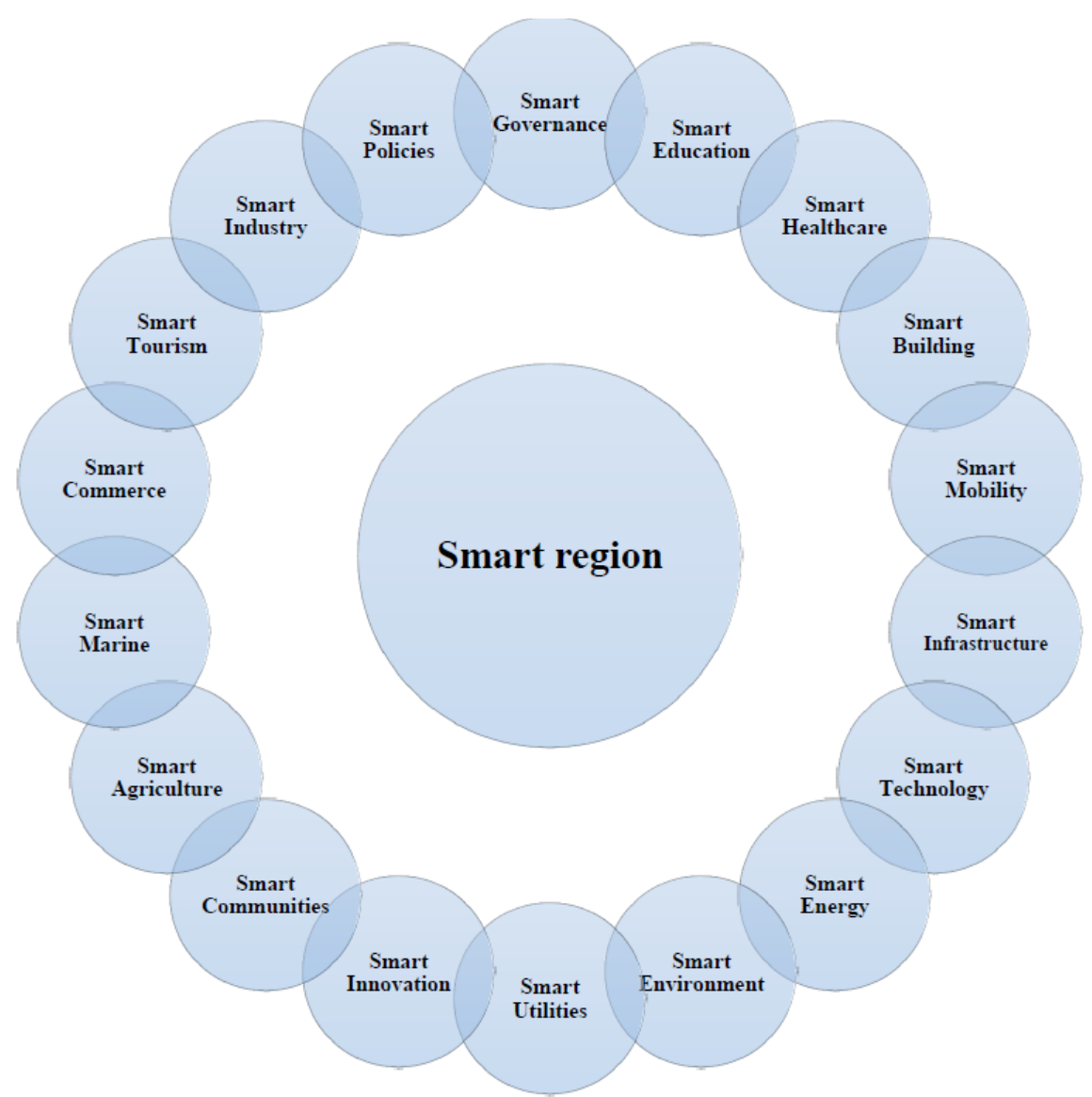

Figure 2. Attributes of Smart region Source: https://www.nwra.ie/ 
Smart regions add digital intelligence to the regions world and use it to solve public problems and achieve a higher quality of life. We have three layers of "smartness":

1. The tech base includes networks of connected devices and sensors

2. Smart applications and data analysis capabilities

3. Adoption and usage, often leading to better decisions and behavior change

Many cities and regions around the world benefit from innovation and digitization strategies. The relationship between characteristics and components of smart region is complex topic. It is very similar to Smart Cities [4]. In practice, components and characteristics are often difficult to distinguish; components, in particular, are not systematically identified. Components can be conceptualized as the building blocks of Smart City initiatives. They comprise the inputs, technologies and processes of specific initiatives, as well as the norms or standards deployed. 'Smart Regions' initiatives provide the catalyst for regional communities to become more resilient and sustainable, affording economic efficiencies, environmental innovations, enhanced public security, smarter mobility, fresh economic activity and 21st century jobs. Smart regions add digital intelligence to existing regional systems, making it possible to do more with less. Connected applications put real-time, transparent information into the hands of users to help them make better choices. These tools can save lives, prevent crime, and reduce the disease burden. They can save time, reduce waste, and even help boost social connectedness. When cities function more efficiently, they also become more productive places to do business. Cities carry the brunt of modern day challenges (ie traffic congestion, air quality) but they also serve as a natural cradle to talent, jobs and innovations. Modern cities are at the very center of 'Geographies of Innovation'. Imperative to a successful wholesale "smart strategy for all" is to take innovations beyond the city centers, however, facilitating larger regions, catering the digital enhancement of our communities, large or small. Smart regions may disrupt some industries even as they present substantial market opportunities. Smart city strategies can only become successful if they prove sufficiently inclusive. Smart region strategies pave the way for such digital inclusion. The main difference between the smart region and the traditional region is the nature of the relationship with the population. In the ordinary region, ICT-based services cannot respond as quickly to changing economic cultural and social conditions as services in the smart region. In this way, the smart, human-centered region is based on ICT infrastructure and the continuous development of the region, while constantly respecting the requirements for environmental and economic sustainability. Customer needs will force a reevaluation of current products and services to meet higher expectations of quality, cost, and efficiency in everything from mobility to healthcare. Smart regions solutions will shift value across the landscape of cities and throughout value chains. Companies looking to enter smart regions markets will need different skill sets, creative financing models, and a sharper focus on civic engagement. By seeing smaller and larger communities collaborate, procure, set innovation agendas, sharing know how, creating economies of scale, and aggregating demand, digital inclusion can be addressed effectively, with smaller communities benefiting from the same digital innovations large regions can typically already enjoy. Smart region strategies help us achieve that goal [5].

\section{CONCLUSION}

In conclusion, the Smart Region is one that uses information and communication technologies to increase operational efficiency, share information with the public, and to improve the quality of government services and the well-being of citizens. The core 
mission of a smart region is to optimize the functions of the region and stimulate economic growth, while improving the quality of life of its population, using smart technology and data analysis.Structurally, the "smart" region is a system of interacting systems. Such interaction of a huge number of systems requires openness and standardization, which are the basic principles of creating smart regions. The Smart Region project, which lacks openness and standardization, very soon becomes cumbersome and expensive. Some of the technologies included and defining the smart region are the high-speed optical, sensor, cable and wireless networks needed to realize the benefits of intelligent transportation systems, smart grids and smart home networks.

\section{REFERENCES}

[1] Markkula, M., \& Kune, H. 2015. Making Smart Regions Smarter: Smart Specialization and the Role of Universities in Regional Innovation Ecosystems. Technology Innovation Management Review, 5(10):7-15. http://doi.org/10.22215/timreview/932

[2] Yndestad H. Smart regions, Conference: Fjordkonferansen 2014 At: Loen. Norway

[3] Kollar M., R. L. Bubbico, N. Arsalides Smart Cities, Smart Investment in Central, Eastern and South-Eastern Europe, A report by the EIB Economics Department, 2018

[4] Directorate-General for Internal Policies: Mapping Smart Cities in the EU. 2014. ISBN 978-92-823-4761-4.

[5] Boorsma B. J. Baekelmans, B. Bennett, D. Papa, P. Erik Lauridsen, R. Gareri Smart Regions: Paving the Way for Successful Digitalization Strategies beyond Smart Cities, The Smart City Association, 2018

[6] Fernández Maldonado, Ana Maria. 2012. ICT and spatial planning in European Cities. Reviewing the New Charter of Athens. Built Environment vol. 38, n. 4.

[7] Atanasova A., Naydenov K. (2020) The Innovative Approaches for the Development of Smart Cities. In: Nedkov S. et al. (eds) Smart Geography. Key Challenges in Geography (EUROGEO Book Series). Springer, Cham 